\title{
Effects of Buffer Compensation Strategies on the Electrical Performance and RF Reliability of AlGaN/GaN HEMTs
}

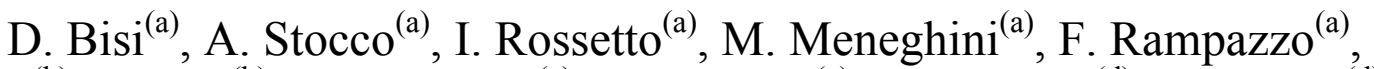

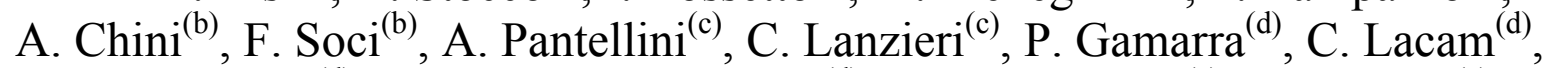 \\ M. Tordjman ${ }^{(\mathrm{d})}$, M.-A. di Forte-Poisson ${ }^{(\mathrm{d})}$, D. De Salvador ${ }^{(\mathrm{e})}$, M. Bazzan $^{(\mathrm{e})}$, \\ G. Meneghesso $^{(a)}$, E. Zanoni ${ }^{(a)}$
}

\section{Introduction}

GaN-based HEMTs are excellent candidates for next-generation high-power microwave applications. Nevertheless, due to the spontaneous n-type conductivity of GaN crystals, devices equipped with unintentionally-doped GaN buffer experience detrimental short-channel effects, undermining both the device performances and their long-term stability. Technological solutions involve the introduction of carbon and/or iron species, which compensate the unintentional donors, render the GaN buffer layer semi-insulating, and improve the confinement of electrons in the 2DEG. Nevertheless, the incorporation of foreign impurities and the related growth conditions may give rise to enhanced crystallographic defect density and enhanced parasitic charge-trapping phenomena. Within this work, we comprehensively investigate the static and dynamic parasitic effects related to the GaN-buffer design, and we discuss the implications on the RF performance and reliability.

\section{Experimental Details}

Devices under test belong to fourteen wafers differing mainly for GaN buffer design. HEMTs were fabricated using the same process steps and layout, with a $0.5 \mu \mathrm{m} \mathrm{Ni} / \mathrm{Au}$ gate; they were grown on silicon carbide substrate and they adopt an $\mathrm{AlGaN} / \mathrm{GaN}$ heterostructure with nominal $25 \% \mathrm{Al}$ concentration and $23 \mathrm{~nm}$ AlGaN thickness, but with different buffer compensation, including either no doping (type I), $3 \times 10^{17} \mathrm{~cm}^{-3} \mathrm{C}$-doping (type II), $2 \times 10^{17} \mathrm{~cm}^{-3}$ Fe-doping (type III), or $10^{18} \mathrm{~cm}^{-3} \mathrm{Fe}$ and $10^{18} \mathrm{~cm}^{-3} \mathrm{C}$ co-doping (type IV).

The performed analysis includes (i) static, doublepulsed, and Load-Pull characterizations, devoted to the evaluation of static- and dynamic- performances, (ii) Drain-Current Transient Spectroscopy (DCTS), performed to identify the involved deep-trap-levels and related defect-states, and (iii) x-rays diffraction (XRD), employed to gather auxiliary information on the crystallographic defectiveness of the samples under test.

\section{Static I-V Analysis}

The parasitic conductivity of GaN buffer strongly impact on the subthreshold behaviour of AlGaN/GaN HEMTs. Fig. 1 shows the $\mathrm{I}_{\mathrm{G}}-\mathrm{V}_{\mathrm{G}}$ and $\mathrm{I}_{\mathrm{S}^{-}}$ $\mathrm{V}_{\mathrm{G}}$ characteristics acquired on four representative samples equipped with unintentionally doped (u.i.d.), $3 \times 10^{17} \mathrm{~cm}^{-3} \mathrm{C}$-doped, $2 \times 10^{17} \mathrm{~cm}^{-3}$ Fe-doped, and $10^{18}$ $\mathrm{cm}^{-3} \mathrm{Fe}-$ and $10^{18} \mathrm{~cm}^{-3} \mathrm{C}$-doped buffer. Devices equipped with u.i.d. buffer feature remarkable source-to-drain leakage current and high DrainInduced Barrier Lowering (DIBL) effect, which are proofs of high parasitic buffer conductivity, poor carrier confinement, and poor pinch-off properties. Source-to-drain leakage-current and DIBL can be gradually mitigated by the adoption of acceptor-like carbon and iron doping, which compensate the spontaneous n-type of u.i.d. buffer [1] [2] [3]. Good subthreshold behavior is achieved with doping concentration equal to or greater than $10^{18} \mathrm{~cm}^{-3}$. In the following, the side effects of buffer doping on the dynamic performance of the devices are reported.

\section{Pulsed I-V and drain current transient spectroscopy}

To investigate the impact of different buffercompensation strategies on the dynamic performance of the devices under test, double pulsed $I_{D}-V_{D}$ measurements [4] have been performed. Dynamic current dispersion has been evaluated in the quiescent bias point $\left(\mathrm{V}_{\mathrm{GQ}} ; \mathrm{V}_{\mathrm{DQ}}\right)=(-6 \mathrm{~V} ; 25 \mathrm{~V})$. Results reveal that wafers adopting iron- and/or carbondoped buffer show, on average, higher current 
dispersion than those adopting u.i.d. buffer (Figure 2).

In order to identify the roots of enhanced chargetrapping and related current dispersion effects, the devices under test have been submitted to drain current transient spectroscopy [5]. Figure 3 depicts drain-current recovery transients performed on representative devices equipped with u.i.d., $3 \times 10^{17}$ $\mathrm{cm}^{-3} \mathrm{C}$-doped, and $10^{18} \mathrm{~cm}^{-3} \mathrm{Fe}-10^{18} \mathrm{~cm}^{-3} \mathrm{C}$-doped buffers, subjected to 100 s-long semi-on-state stress $\left(\mathrm{V}_{\mathrm{GF}} ; \mathrm{V}_{\mathrm{DF}}\right)=\left(\mathrm{V}_{\mathrm{TH}}+0.5 \mathrm{~V} ; 25 \mathrm{~V}\right)$. Distinct electron detrapping processes are observed in the different samples. By performing the measurements at different base-plate temperature, we characterized the thermal-activation of these detrapping processes, gathering the activation-energy and the apparent capture cross-section of involved deep-levels. The detected deep-levels, labelled E2, E3, E4 and E5 can be mainly ascribed to III-nitride defects. Similar results have been reported in several research works on deep-level transient spectroscopy in (Al)GaN layers [6] [7] [8] [9].

Different research works reported that the irondoping may be the cause for enhanced currentdispersion effects [10] [11] [12]. Consistently with our results, enhanced dispersion-effects are ascribed to enhanced density of the deep-trap-level $\mathrm{E}_{\mathrm{C}}-0.56$ $\mathrm{eV} / 10^{-15} \mathrm{~cm}^{2}$, labelled in this work as E2. Interestingly, we noted that the trap E2 could not be exclusively ascribed to iron [13]: several scientific papers claim the presence of the $\mathrm{E} 2$ in GaN bulk layers and GaN-based devices grown by means of different techniques, without the intentional introduction of foreign, dopant species [6] [14] [15].

These hypotheses are supported by structural analysis: $\mathrm{x}$-rays diffraction have been performed on wafers equipped with u.i.d., $3 \times 10^{17} \mathrm{~cm}^{-3} \mathrm{C}$-doped, and $10^{18} \mathrm{~cm}^{-3} \mathrm{Fe}$ - and C-doped buffer. Figure 4 depicts the diffracted intensity as a function of the incidence angle with the detector fixed at the Bragg angle for the (006) $\mathrm{GaN}$ reflection ( $\omega$-scan). This type of scan is sensitive to the presence of locally tilted diffraction domains in the crystal lattice. This feature can be related to the buffer dislocation density [16]. Interestingly, doped wafers feature higher Full Width at Half Maximum (FWHM) than u.i.d. wafer. This would suggest that the doping process, either due (i) to altered sub-optimal growth conditions, (ii) to the introduction of nucleation centers, or (iii) to the Fermi-Level effect on the dislocation formation energy, may leads to enhanced dislocation density, and possibly to enhanced
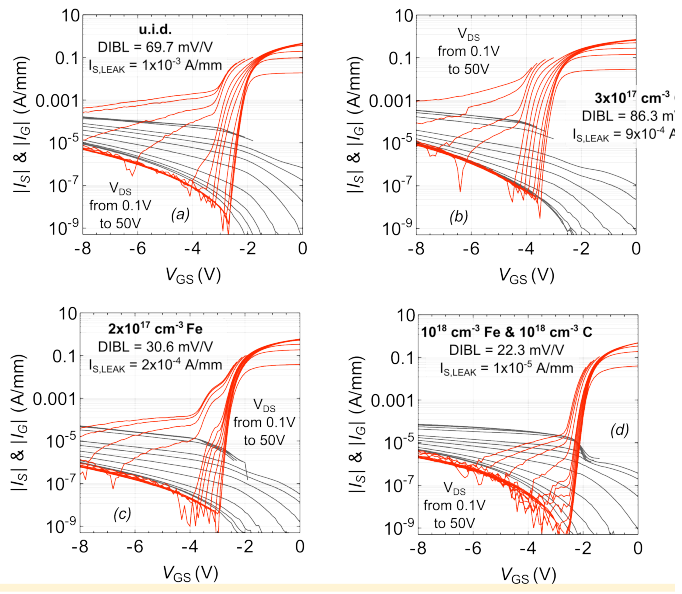

Fig. 2. Static $\mathrm{I}_{\mathrm{G}}-\mathrm{V}_{\mathrm{G}}$ and $\mathrm{I}_{\mathrm{S}}-\mathrm{V}_{\mathrm{G}}$ characteristics of representative samples equipped with unintentionally doped (u.i.d.), $3 \times 10^{17} \mathrm{~cm}^{-3} \mathrm{C}$-doped, $2 \times 10^{17} \mathrm{~cm}^{-3} \mathrm{Fe}-$ doped, and $10^{18} \mathrm{~cm}^{-3} \mathrm{Fe}$ - and $10^{18} \mathrm{~cm}^{-3} \mathrm{C}$-doped buffer. $\mathrm{V}_{\mathrm{DS}}$ is stepped from $0.1 \mathrm{~V}$ to $50 \mathrm{~V}$. Current compliance has been set at $0.1 \mathrm{~A} / \mathrm{mm}$ to avoid device degradation. Strong subthreshold issues (high sourceto-drain leakage-current, and high DIBL effects) are detected in u.i.d. buffer, and are mitigated by the introduction of carbon and iron compensating species.
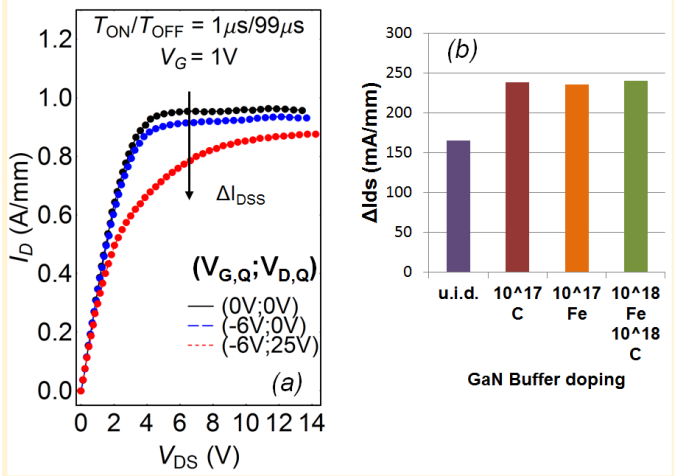

Fig. 2. (a) Representative double-pulse $\mathrm{I}_{\mathrm{D}}-\mathrm{V}_{\mathrm{D}}$ measurement, showing the collapse of drain-current when the devices are exposed to off-state. (b) Wafers adopting iron- and/or carbon-doped buffer experience, on average, higher current dispersion ( $\Delta \mathrm{I}_{\mathrm{DSs}}$ extracted at $\left.\left(\mathrm{V}_{\mathrm{G}}, \mathrm{V}_{\mathrm{D}}\right)=\left(1 \mathrm{~V}, \mathrm{~V}_{\mathrm{D}, \mathrm{KNEE}}\right)\right)$ than those adopting u.i.d. huffer

electrically-active deep-trap-state density [17]. Rudzinski et al. [18] and Mei et al. [19] support these inferences by means of SEM, DIC, TEM, AFM microscopy and RHEED, reporting enhanced concentration of threading dislocation in iron-doped $\mathrm{GaN}$ layers. 

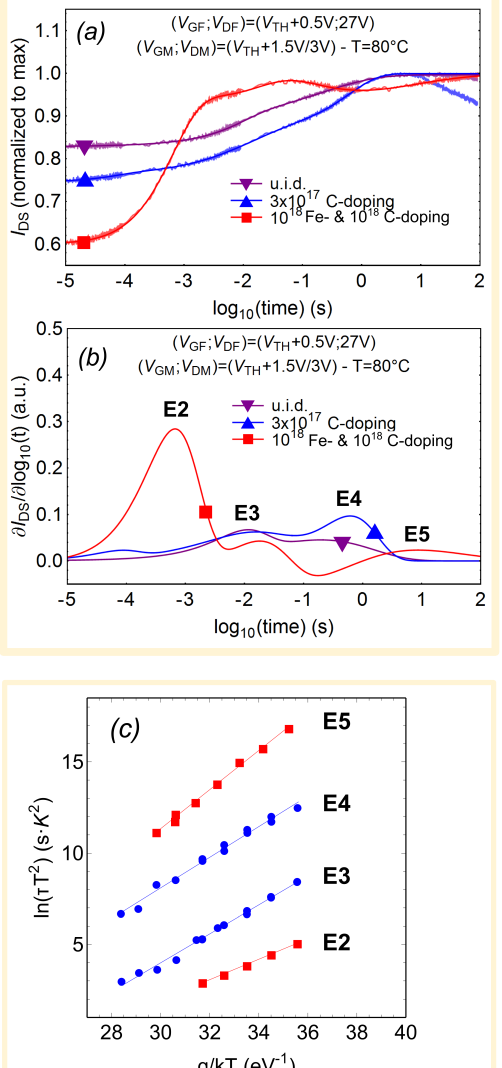

\begin{tabular}{|c|c|c|c|c|}
\hline Deep-level & $\mathbf{E 2}$ & $\mathbf{E 3}$ & $\mathbf{E 4}$ & $\mathbf{E 5}$ \\
\hline $\begin{array}{c}\text { apparent } \\
(\mathbf{e V})\end{array}$ & 0.56 & 0.79 & 0.84 & 1.07 \\
\hline $\begin{array}{c}\text { apparent } \\
\boldsymbol{\sigma}_{\mathbf{c}}\left(\mathbf{c m}^{2}\right)\end{array}$ & $5 \times 10^{-15}$ & $6 \times 10^{-13}$ & $4 \times 10^{-14}$ & $2 \times 10^{-12}$ \\
\hline \multicolumn{4}{|c|}{ apparent concentration in GaN buffer with } \\
\hline u.i.d. & $/$ & low & low & $/$ \\
\hline $\mathbf{3 \times 1 0 ^ { 1 7 }} \mathbf{C}$ & $/$ & low & mid & $/$ \\
\hline $\mathbf{1 0}^{\mathbf{1 8}} \mathbf{F e} \boldsymbol{\&} \mathbf{1 0}^{\mathbf{1 8}} \mathbf{C}$ & high & low & $/$ & low \\
\hline
\end{tabular}

Fig. 3. (a) drain-current transients performed on representative devices equipped with u.i.d., $3 \times 10^{17} \mathrm{~cm}$ ${ }^{3} \mathrm{C}$-doped, and $10^{18} \mathrm{~cm}^{-3} \mathrm{Fe}$ - and C-doped buffer, subjected to 100s-long semi-on-state stress $\left(\mathrm{V}_{\mathrm{GF}} ; \mathrm{V}_{\mathrm{DF}}\right)=\left(\mathrm{V}_{\mathrm{TH}}+0.5 \mathrm{~V} ; 25 \mathrm{~V}\right)$, and $(\mathrm{b})$ related spectroscopy. (c) Thermal-activation of detected deeplevels.

Similarly to E2, also the level E4 has been observed in unintentionally doped $\mathrm{GaN}$ crystals, again suggesting the involvement of gallium-nitride native defects as side effect of carbon doping process. Higher FWHM in C-doped wafers have also been observed by Wickenden et al. [2] and Chen et al. [20]. Complementary information on the effects of iron and carbon doping on the dynamic performance of $\mathrm{AlGaN} / \mathrm{GaN}$ HEMTs are discussed by Uren et al. [21] [22], Verzellesi et al. [23], Meneghesso et al. [24], and Meneghini et al. [13].

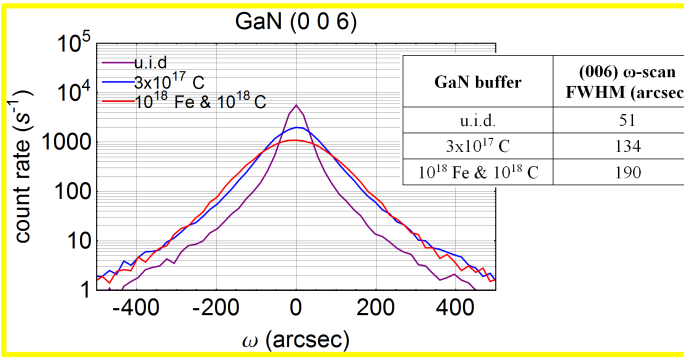

Fig. 4. X-ray diffraction performed on u.i.d., $3 \times 10^{17}$ $\mathrm{cm}^{-3} \mathrm{C}$-doped, and $10^{18} \mathrm{~cm}^{-3} \mathrm{Fe}$-doped wafers. The $\Omega$ scan on the (006) GaN reflection, and related Full Width at Half Maximum (FWHM) suggest that doped wafers feature higher dislocation density, hence likely higher electrically active defect-states, than u.i.d. wafers.

\section{RF stress tests}

Devices from each wafer were submitted to a $24 \mathrm{~h}$ $\mathrm{CW} \mathrm{RF}$ test at $2.5 \mathrm{GHz}$ with quiescent bias at $\left(\mathrm{V}_{\mathrm{DS}}=30 \mathrm{~V}, \mathrm{I}_{\mathrm{D}}=30 \% \mathrm{I}_{\mathrm{DSS}}\right)$ and driven into a $6 \mathrm{~dB}$ compression point. Base-plate temperature was set to $40^{\circ} \mathrm{C}$. No correlation was found between the dissipated power and the RF output power degradation (Figure 5).

Devices subjected to 24-hours RF test experienced a degradation on the $\mathrm{RF}$ output power $\left(\Delta \mathrm{P}_{\mathrm{OUT}}\right)$ ranging from $-0.05 \mathrm{dBm}$ to $-1.1 \mathrm{dBm}$. From static measurements performed prior to and after the stress, no worsening of the gate leakage current was detected, even in devices with $\Delta \mathrm{P}_{\text {OUT }}=-1 \mathrm{dBm}$ (Figure 6a). This suggests that the gate-edge degradation [25] is not the dominant degradation mechanism. Likewise, no correlation has been found between the degradation of RF performances and the variation of the dc parameters, such as $\mathrm{I}_{\mathrm{D}}, \mathrm{g}_{\mathrm{m}}$ or $\mathrm{V}_{\mathrm{TH}}$. Conversely, the main evidence of device degradation is a significant increase of the current-collapse, suggesting the worsening of charge-trapping effects. Figure $6 \mathrm{~b}$ shows the pulsed $\mathrm{I}_{\mathrm{D}}-\mathrm{V}_{\mathrm{D}}$ characteristics of a representative device with u.i.d buffer which experienced a $\Delta \mathrm{P}_{\text {OUT }}$ of $-1 \mathrm{dBm}$. Though no significant degradation is found in the reference quiescent-bias point, $\left(\mathrm{V}_{\mathrm{G}, \mathrm{Q}} ; \mathrm{V}_{\mathrm{D}, \mathrm{Q}}\right)=(0 \mathrm{~V} ; 0 \mathrm{~V})$, a remarkable drain-current degradation $\left(-25 \%\right.$ at $\mathrm{V}_{\mathrm{DS}}=$ $4 \mathrm{~V})$ is found in the hot quiescent bias-point $\left(\mathrm{V}_{\mathrm{G}, \mathrm{Q}} ; \mathrm{V}_{\mathrm{D}, \mathrm{Q}}\right)=\left(\mathrm{V}_{\mathrm{TH}}+0.5 ; 25 \mathrm{~V}\right)$. Figure 7 shows the correlation between the increase of current-collapse and the decrease of RF output power among all tested wafers.

Interestingly, the devices equipped with iron- and 


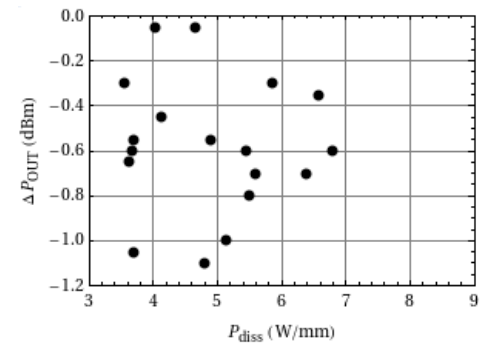

Fig. 7. No correlation is found between power dissipated during the rf stress and the degradation of the rf output power.
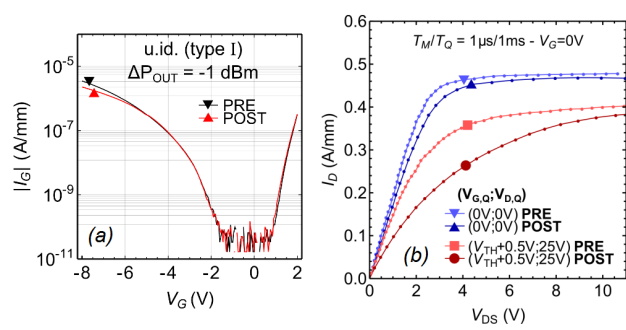

Fig. 7. (a) $\mathrm{I}_{\mathrm{G}}-\mathrm{V}_{\mathrm{G}}$ characteristics and (b) pulsed $\mathrm{I}_{\mathrm{D}}$ vs $\mathrm{V}_{\mathrm{DS}}$ characteristics acquired prior to and after the stress of a representative u.i.d. sample experiencing a $\Delta \mathrm{P}_{\text {OUT }}$ of $-1 \mathrm{dBm}$. The worsening of the currentcollapse is the only relevant evidence of device degradation induced by $\mathrm{rf}$ operations.
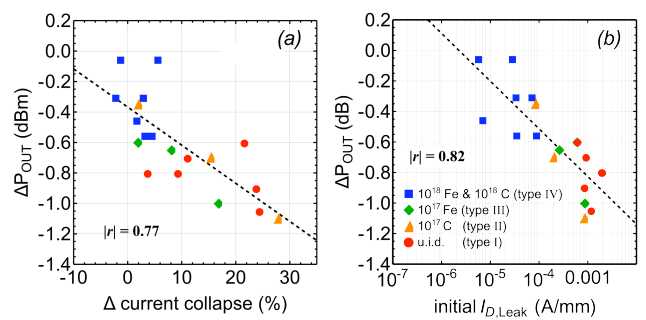

Fig. 7. Good correlation is verified between (a) $\Delta \mathrm{P}_{\text {OUT }}$ and the worsening of current-collapse after rf test, and (b) $\mathrm{I}_{\mathrm{D}, \text { LEAK }}$ and $\mathrm{P}_{\mathrm{OUT}}$ degradation.

carbon co-doped GaN buffer-layer experience lower degradation than those equipped with unintentionally doped (u.i.d.) buffer. This strongly suggests the involvement of buffer-related degradation mechanisms: in fact, though featuring similar gate leakage current, devices equipped with u.i.d. buffer experience dramatic source-to-drain subthreshold leakage current $\left(\mathrm{I}_{\mathrm{D}, \mathrm{LEAK}}\right)$, which is order of magnitudes higher than what found in devices equipped with optimized, iron and carbon co-doped buffers (see Fig 1). Good correlation between $\mathrm{I}_{\text {D,LEAK }}$ and $\mathrm{P}_{\text {OUT }}$ degradation (Fig 6b) strongly suggests the involvement of hot-electrons degradation mechanisms: accelerated by the high electric field existing during off-state conditions, the parasitic electrons flowing from source-to-drain could gain enough kinetics energy to generate defect-states in the $\mathrm{AlGaN} / \mathrm{GaN}$ active region, through direct damage of weak lattice bonds or dehydrogenation of Ga vacancies or N antisites complexes [26] [27].

\section{Conclusions}

The effects of buffer compensation strategies on the Electrical Performance and RF Reliability of AlGaN/GaN HEMTs have been studied by means of static and dynamic I-V measurements, drain-current transient spectroscopy, XRD, and RF stress tests. Devices equipped with $\mathrm{C}$-doped and Fe-doped GaN buffer feature improved subthreshold behaviour (lower source-to-drain leakage current and lower DIBL) and improved RF reliability. As a drawback, devices equipped with $\mathrm{Fe}$ - and $\mathrm{C}$-doping experience higher dynamic current dispersion, related to enhanced charge-trapping at the deep levels E2 (0.56 $\left.\mathrm{eV} / 10^{-15} \mathrm{~cm}^{2}\right)$ and $\mathrm{E} 4\left(0.84 \mathrm{eV} / 10^{-14} \mathrm{~cm}^{2}\right)$. The comprehensive characterization of parasitic effects of buffer compensation will play a key role also for the development of GaN-based HEMTs devoted to power-switching applications [28].

\section{Acknowledgment}

This work was supported by the EDA project MANGA, and by ONR N000141410647 "GaN HEMT reliability physics: from failure mechanisms to testing methods, test structures and acceleration laws" under the supervision of Dr. P. Maki.

\section{References}

[1] S. Heikman, S. Keller, T. Mates, S.P. DenBaars, U.K Mishra, "Growth and characteristics of Fe-doped GaN," $J$. Cryst. Growth, vol. 248, p. 513, 2003.

[2] A.E. Wickenden, D.D. Koleske, R.L. Henry, M.E. Twigg, M. Fatemi, "Resistivity control in unintentionally doped GaN films grown by MOCVD," vol. 260, p. 54, 2004.

[3] M J Uren, D G Hayes, R S Balmer, D J Wallis, K P Hilton, J O Maclean, T Martin, C Roff, "Control of Short-Channel Effects in GaN/AlGaN HFETs," in European Microwave Integrated Circuits Conference, 2006, p. 65.

[4] D. Bisi, A. Stocco, M. Meneghini, F. Rampazzo, A. Cester, G. Meneghesso, E. Zanoni, "High-Voltage Double-Pulsed Measurement System for GaN-based Power HEMTs," in IEEE IRPS 2014, 2014, p. CD.11.1. 
[5] D. Bisi, M. Meneghini, C. De Santi, A. Chini, M. Dammann, P. Brückner, M. Mikulla, G. Meneghesso, E. Zanoni, "Deep-Level Characterization in GaN HEMTsPart I: Advantages and Limitations of Drain Current Transient Measurements," IEEE Trans. Electron Devices, vol. 60, no. 10, p. 3166, 2013.

[6] P. Hacke, T. Detchprohm, K. Hiramatsu, N. Sawaki, "Analysis of deep levels in n-type $\mathrm{GaN}$ by transient capacitance methods," J. Appl. Phys., vol. 76, p. 304, 1994.

[7] F. D. Auret, S. A. Goodman, F. K. Koschnick, J-M. Spaeth, B. Beaumont, P. Gibart, "Electrical characterization of two deep electron traps introduced in epitaxially grown n-GaN during He-ion irradiation," Appl. Phys. Lett., vol. 73, p. 3745, 1998.

[8] N.M. Shmidt, D.V. Davydov, V.V. Emtsev, I.L. Krestnikov, A.A. Lebedev, W.V. Lundin, D.S. Poloskin, A.V. Sakharov, A.S. Usikov, A.V. Osinsky, "Effect of Annealing on Defects in As-Grown and gamma-Ray Irradiated n-GaN Layers," Phys. stat. sol. (b), vol. 216, p. $533,1999$.

[9] M. R. Hogsed, Y. K. Yeo, M. Ahoujja, M.-Y. Ryu, J. C. Petrosky, R. L. Hengehold, "Radiation-induced electron traps in $\mathrm{A} 10.14 \mathrm{Ga} 0.86 \mathrm{~N}$ by $1 \mathrm{MeV}$ electron radiation," Appl. Phys. Lett., vol. 86, p. 261906, 2005.

[10] A. Chini, V. Di Lecce, F. Soci, D. Bisi, A. Stocco, M. Meneghini, G. Meneghesso, E. Zanoni, A. Gasparotto, "Experimental and numerical correlation between currentcollapse and fe-doping profiles in GaN," in IEEE International Reliability Physics Symposium (IRPS) 2012, 2012, p. CD.2.1.

[11] D. W. Cardwell, A. Sasikumar, A. R. Arehart, S. W. Kaun, J. Lu, S. Keller, J. S. Speck, U. K. Mishra, S. A. Ringel, J. P. Pelz, "Spatially-resolved spectroscopic measurements of Ec $0.57 \mathrm{eV}$ traps in $\mathrm{AlGaN} / \mathrm{GaN}$ high electron mobility transistors," Appl. Phys. Lett., vol. 102, p. 193509, 2013.

[12] M. Silvestri, M. J. Uren, M. Kuball, "Iron-induced deeplevel acceptor center in $\mathrm{GaN} / \mathrm{AlGaN}$ high electron mobility transistors: Energy level and cross section," Appl. Phys. Lett., vol. 102, p. 073501, 2013.

[13] M. Meneghini, I. Rossetto, D. Bisi, A. Stocco, A. Chini, A Pantellini, C. Lanzieri, A. Nanni, G. Meneghesso, E. Zanoni, "Buffer Traps in Fe-Doped AlGaN/GaN HEMTs: Investigation of the Physical Properties Based on Pulsed and Transient Measurements," IEEE Trans. Electron Devices, vol. 61, p. 4070, 2014.

[14] H. K. Cho, K. S. Kim, C.-H. Hong, and H. J. Lee, "Electron traps and growth rate of buffer layers in unintentionally doped GaN," J. Crystal Growth, vol. 223, p. 38,2001 .

[15] D. Johnstone, S. Biyikli, S. Dogan, Y. T. Moon, F. Yun, and $\mathrm{H}$. Morkoç, "Comparison of deep levels in $\mathrm{GaN}$ grown by MBE, MOCVD, and HVPE," Proc. SPIE 5739, LightEmitting Diodes: Research, Manufacturing, and Applications IX, 7, 2005.

[16] M. A. Moram, M. E. Vickers, "X-ray diffraction of IIInitrides," Rep. Prog. Phys., vol. 72, p. 036502, 2009.

[17] A. F. Wright, U. Grossner, "The effect of doping and growth stoichiometry on the core structure of a threading edge dislocation in GaN," Appl. Phys. Lett., vol. 73, p.
2751, 1998.

[18] M. Rudziński, V. Desmaris, P.A. van Hal, J. L. Weyher, P. R. Hageman, K. Dynefors, T.C. Rodle, H.F.F. Jos, H. Zirath, P.K. Larsen, "Growth of Fe doped semi-insulating $\mathrm{GaN}$ on sapphire and $4 \mathrm{H}-\mathrm{SiC}$ by MOCVD," phys. stat. sol. (c), vol. 3, p. 2231, 2006.

[19] F. Mei, Q. M. Fu, T. Peng, C. Liu, M. Z. Peng, J. M. Zhou, "Growth and characterization of AlGaN/GaN heterostructures on semi-insulating $\mathrm{GaN}$ epilayers by molecular beam epitaxy," J. Appl. Phys., vol. 103, p. 094502, 2008

[20] J.-T. Chen, U. Forsberg, E. Janzén, "Impact of residual carbon on two-dimensional electron gas properties in AlxGa1xN/GaN," Appl. Phys. Lett., vol. 102, p. 193506, 2013.

[21] M. J. Uren, J. Möreke, M. Kuball, "Buffer Design to Minimize Current Collapse in GaN/AlGaN HFETs," IEEE Trans. Electron Devices, vol. 59, no. 12, p. 3327, 2012.

[22] M. J. Uren, M. Silvestri, M. Caesar, G. A. M. Hurkx, J. A. Croon, J. Sonsky, M. Kuball, "Intentionally Carbon-Doped AlGaN/GaN HEMTs: Necessity for Vertical Leakage Paths," IEEE Electron Device Letters, vol. 35, no. 3, p. 327, 2014.

[23] G. Verzellesi, L. Morassi, G. Meneghesso, M. Meneghini, E. Zanoni, G. Pozzovivo, S. Lavanga, T. Detzel, O. Haberlen, G. Curatola, "Influence of Buffer Carbon Doping on Pulse and AC Behavior of Insulated-Gate Field-Plated Power AlGaN/GaN HEMTs," IEEE Electron Device Lett., vol. 35, p. 443, 2014.

[24] G. Meneghesso, M. Meneghini, D. Bisi, R. Silvestri, A. Zanandrea, O. Hilt, E. Bahat-Treidel, F. Brunner, A Knauer, J. Wuerfl, E. Zanoni, "GaN-Based Power HEMTs: Parasitic, Reliability and High Field Issues," ECS Transactions, vol. 58, p. 187, 2013.

[25] E. Zanoni, M. Meneghini, A. Chini, D. Marcon, G. Meneghesso, "AlGaN/GaN-Based HEMTs Failure Physics and Reliability: Mechanisms Affecting Gate Edge and Schottky Junction," IEEE Trans. Electron Devices, vol. 60, p. 3119, 2013.

[26] Y. Puzyrev, S. Mukherjee, J. Chen, T. Roy, M. Silvestri, R. D. Schrimpf, D. M. Fleetwood, J. Singh, J. M. Hickley, A. Paccagnella, S. T. Pantelides, "Gate Bias Dependence of Defect-Mediated Hot-Carrier Degradation in GaN HEMTs," IEEE Trans. Electron Devices, vol. 61, p. 1316, 2014.

[27] Y. S. Puzyrev, T. Roy, M. Beck, B. R. Tuttle, R. D. Schrimpf, D. M. Fleetwood, S. T. Pantelides, "Dehydrogenation of defects and hot-electron degradation in GaN high-electron-mobility transistors," J. Appl. Phys., vol. 109, p. 034501, 2011.

[28] J. Würfl, O. Hilt, E. Bahat-Treidel, R. Zhytnytska, P. Kotara, F. Brunner, O. Krueger, M. Weyers, "Techniques towards $\mathrm{GaN}$ power transistors with improved high voltage dynamic switching properties," in IEEE Electron Device Meeting (IEDM 2013), 2013, p. 6.1.1. 